\title{
PRELIMINARY MEASUREMENTS ON TEMPERATURE AND SELECTIVE RADIATION OF INCANDESCENT LAMPS.
}

\author{
By C. W. Waidner and G. K. Burgess.
}

The high efficiency attained in some recent metal filament lamps raises the question whether this is to be attributed to selective radiation or to a higher working temperature of the filament, or to both. As in this region of high temperatures almost no data are available at present, the results of some preliminary measurements on the temperature and selective radiation of a number of metal filament lamps are given in this paper.

METHOD OF MEASUREMENT.

The method of measurement is as follows:

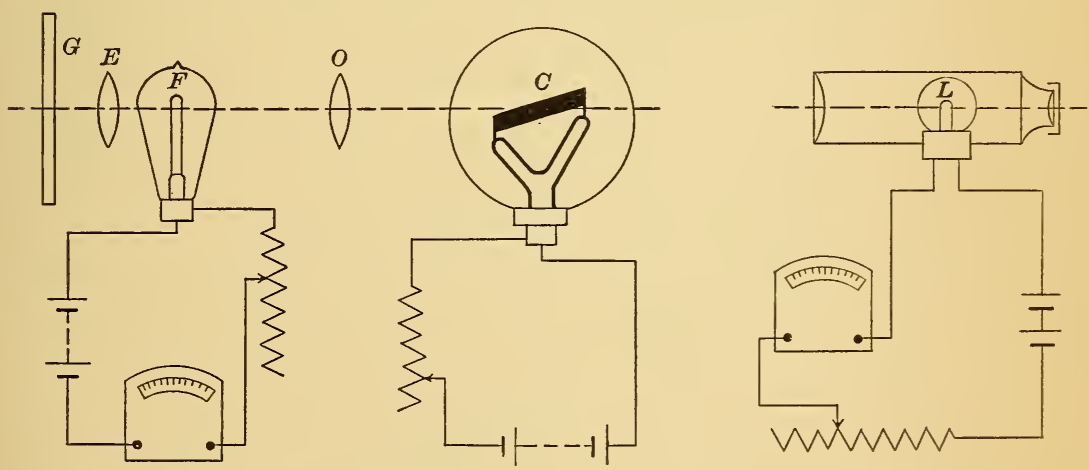

Fig. 1.

The filament $F$ of the lamp under observation is mounted in front of the carbon ribbon $C$, which is itself within an evacuated globe, in such a way that, by means of the lenses $O$ and $E$, the filament is seen superimposed on the carbon ribbon $C$. This ribbon may be heated electrically to any desired temperature, which is measured 
by means of the Holborn-Kurlbaum optical pyrometer, ${ }^{1}$ the principal of which is briefly as follows:

The current in the pyrometer lamp $L$ is adjusted until the filament is of the same brightness as the incandescent body under observation. From a previous calibration by comparison with thermocouples and a black body source, the relation between the current in the filament and its equivalent black body temperature is known.

An observation at one temperature consists in setting the two filaments $F$ and $L$ to the same brightness as $C$, and measuring the currents in $F$ and $L$. The temperatures of $C$ and of $F$ are then known from the calibration of $L$. From a series of such measurements at different temperatures the temperature-current curve for the filament $F$ may be drawn.

Temperature Scale.-The lamp $L$ being calibrated by comparison with a black body, when sighted on another incandescent body, reads not its true temperature, but something lower, by an amount depending on the emissive power of the body. By the term "black body temperature," is therefore meant the temperature at which a black body would send out radiation of the same intensity as that from the object observed for a given wave length. A body at a given temperature will in general have a different black body temperature for each color, that for red being lower than for green or blue. In this paper the term temperature, unless otherwise qualified, is taken to mean the black body temperature centigrade as given by an optical pyrometer using red light, $\lambda=0.66 \mu$.

To study the selective radiation for different colors, the filament $F$ was calibrated with red, green, and blue light, obtained by interposing monochromatic glasses at $G$.

The measurements were made in the range $700^{\circ}-1850^{\circ} \mathrm{C}$, which was the safe upper limit of the carbon ribbon $C$. Higher temperatures of $F$ were then obtained by extrapolation of the currenttemperature relation. As to the reliability of such extrapolation, we have found that lamps calibrated to $\mathrm{I}_{300^{\circ}}$ were still in agreement to within $\mathrm{I}^{\circ}$ or $2^{\circ}$ when extrapolated $300^{\circ}$, and further that these extrapolations are in satisfactory agreement with other methods of measuring temperature.

\footnotetext{
I The subject of Optical Pyrometry is treated at length in Bulletin of Bureau of Standards, 1, p. I89-254; 1905.
} 
Waidner.
Burgess. Temperature and Radiation of Incandescent Lamps.

Precision of Method.-As an illustration of the results attainable by this method we give in Table I the measurements made on a roo-volt metal filament lamp, very probably tungsten.

\section{TABLE 1.}

Calibration of Metal Filament Lamp, No. 11 (red radiation).

\begin{tabular}{c|c|c|c}
\hline Current in Filament. & $\begin{array}{c}\text { Observed Temperature } \\
\text { of Filament. }\end{array}$ & $\begin{array}{c}\text { Calculated } \\
\text { Temperature. }\end{array}$ & $\begin{array}{c}\text { Observations } \\
\text { Calculated. }\end{array}$ \\
\cline { 2 - 4 } 0.1302 & $847^{\circ}$ & 848.2 & -1.2 \\
0.1510 & $921^{\circ}$ & 919.2 & +1.8 \\
0.1895 & $1049^{\circ}$ & 1051.2 & -2.2 \\
0.2270 & $1166^{\circ}$ & 1167.2 & -1.2 \\
0.2625 & $1267^{\circ}$ & $1269: 9$ & -2.9 \\
0.3144 & $1413^{\circ}$ & $1410: 7$ & +2.3 \\
0.4013 & $1621^{\circ}$ & 1625.2 & -4.2 \\
0.4561 & $1750^{\circ}$ & 1750.2 & -0.2 \\
0.4812 & $1811^{\circ}$ & 1805.7 & +5.3 \\
\hline
\end{tabular}

These observations satisfy the following equation:

$I=-0.0285+0.000104 \mathrm{I} t+0.0000000990 t^{2}$ for red radiation $(\lambda=$ $0.66 \mu$ ), where $I$ is the current in amperes and $t$ is the temperature.

\section{SELECTIVE RADIATION.}

Regarding the significance of selective radiation and its bearing upon the problem in hand, the radiation of platinum for red, green, and blue, as compared with black body radiation, may serve as an extreme illustration. In the following table are grouped some results obtained from measurements of the black body temperatures of platinum for red, green, and blue at various known temperatures.

TABLE II.

Radiation from Platinum.

\begin{tabular}{c|c|c|c}
\hline \multirow{2}{*}{$\begin{array}{c}\text { Actual Temperature of } \\
\text { Platinum }\end{array}$} & \multicolumn{3}{|c}{ Black Body Temperatures } \\
\cline { 2 - 4 } & Red $\lambda=0.66 \mu$ & Green $\lambda=0.55 \mu$ & Blue $\lambda=0.47 \mu$ \\
\hline 1100 & 1008 & 1029 & $\ldots \ldots$ \\
1400 & 1255 & 1285 & 1300 \\
1700 & 1505 & 1545 & 1575 \\
\hline
\end{tabular}


We may interpret these results as follows :

As a first approximation suppose that the platinum is at a true temperature of $\mathrm{I} \mathrm{O0} 0^{\circ}$, then its radiation for green light is equal in intensity to the radiation of a black body at $1545^{\circ}$. The platinum radiation will be somewhat greater than that of this black body for blue light (viz equivalent to a black body at $1575^{\circ}$ ) and somewhat less for red (viz $\mathrm{I} 5 \mathrm{O} 5^{\circ}$ ). The total luminous radiation of the two is therefore not very different, and as the maximum sensibility of the eye is in the green their photometric appearance will be very nearly alike. Now the maximum of energy for both is in the infra-red, and for these long wave lengths the black body temperature of the platinum falls still more behind that of the black body. It will be seen therefore that the energy of luminous radiation is distributed more favorably for platinum than for a black body.

In the calibration of the carbon filament pyrometer lamps against a black body, no appreciable difference (less than $2^{\circ} \mathrm{C}$.) could be detected in the current-temperature calibration equation using red, green, and blue light. It does not follow from this, however, that the radiation from carbon is the same as that from a black body; on the contrary carbon is known to depart considerably from ideal blackness, although in the visible spectrum it shows no appreciable evidence of selective radiation, and for this reason is sometimes called a "gray body."

\section{TUNGSTEN LAMPS.}

Four tungsten filaments gave the following current-temperature TABLE III.

Equations for Tungsten Lamps.

\begin{tabular}{|c|c|c|}
\hline Lamp No. & Color & Equation \\
\hline 1 & Red & $I=1.008-0.000391 \mathrm{t}+0.000000548 \mathrm{t}^{2}$ \\
\hline 5 & Red & $I=1.344-0.000396 \mathrm{t}+0.000000518 \mathrm{t}^{2}$ \\
\hline 10 & Red & $I=0.802-0.000437 t+0.000000490 t^{2}$ \\
\hline 10 & Green & $I=0.775-0.000390 t+0.000000465 t^{2}$ \\
\hline 10 & Blue & $I=0.644-0.000225 \mathrm{t}+0.000000411 \mathrm{t}^{2}$ \\
\hline 11 & Red & $I=-.028+0.000104 t+0.0000000990 t^{2}$ \\
\hline 11 & Green & $\mathrm{I}=-.060+0.000152 \mathrm{t}+0.0000000781 \mathrm{t}^{2}$ \\
\hline 11 & Blue & $I=-.056+0.000148 t+0.0000000778 t^{2}$ \\
\hline
\end{tabular}


relation, where $I$ is the current in amperes in the filament and $t$ is its corresponding black body temperature for radiation (color) studied.

All but lamp No. II were low voltage experimental lamps, designed with a view to studying the behavior of tungsten at high temperatures. The experimental data for lamp No. II are given below. (See Table I et seq.) At normal voltage (Ioo v.) the current in this lamp was 0.644 ampere, from which the corresponding temperature given by its equation is $2 \mathrm{I} 35^{\circ} \mathrm{C}$., indicating a true temperature of the filament of about $2300^{\circ} \mathrm{C}$. (See Table IV.) At 100 volts the candlepower of this lamp was 68 and its consumption 0.95 watt per candle (mean horizontal), from data furnished by Dr. Hyde, of this Bureau. Lamp No. ro was burned at a temperature of $2400^{\circ} \mathrm{C}$. (about $2570^{\circ} \mathrm{C}$. true temperature) for $\mathrm{I} / 2$ hours when it burned out.

Selective Radiation.- The selective radiation of tungsten was studied as in the case of platinum by measuring black body temperatures of the filament for red, green, and blue light. The results as given by the equations of Table III are shown in Table IV.

TABLE IV.

Selective Radiation of Tungsten.

\begin{tabular}{|c|c|c|c|c|}
\hline \multirow{2}{*}{ Lamp No. } & \multicolumn{3}{|c|}{ Black Body Temperatures } & \multirow{2}{*}{$\begin{array}{c}\text { Approximate True } \\
\text { Temperatures }\end{array}$} \\
\hline & $\operatorname{Red}(\lambda=0.66)$ & Green $(\lambda=0.55)$ & Blue $(\lambda=0.47)$ & \\
\hline 10 & $1300^{\circ} \mathrm{C}$ & $1310^{\circ} \mathrm{C}$ & $1319^{\circ} \mathrm{C}$ & $1355^{\circ} \mathrm{C}$ \\
\hline 11 & "6 & $1311^{\circ}$ & $1319^{\circ}$ & $1355^{\circ}$ \\
\hline 10 & $1700^{\circ}$ & $1714^{\circ}$ & $1723^{\circ}$ & $1770^{\circ}$ \\
\hline 11 & “ & $1724^{\circ}$ & $1734^{\circ}$ & $1800^{\circ}$ \\
\hline 10 & $2100^{\circ}$ & $2123^{\circ}$ & $2141^{\circ}$ & $2220^{\circ}$ \\
\hline 11 & “ & $2146^{\circ}$ & $2161^{\circ}$ & $2280^{\circ}$ \\
\hline 10 & $2500^{\circ}$ & $2532^{\circ}$ & $2565^{\circ}$ & $2690^{\circ}$ \\
\hline 11 & “ & $2576^{\circ}$ & $2594^{\circ}$ & $2780^{\circ}$ \\
\hline 10 & $2900^{\circ}$ & $2943^{\circ}$ & $2994^{\circ}$ & $3190^{\circ}$ \\
\hline
\end{tabular}

The appearance of the filament of lamp No. II when cold was more polished than that of No. IO, and the table shows No. II to 
act the more like a bright metal such as platinum. Another lamp whose filament resembled that of No. Io gave sensibly identical values with the latter. The last column in Table IV, giving the approximate values of the actual temperatures of the tungsten filaments, is obtained by adding to the black body temperature for blue light twice the difference between the red and blue readings, a relation found to hold fairly well for platinum, which shows this selective effect much more than does tungsten. (See Table II.)

A filament, the composition of which was stated to be $30 \%$ tungsten and $70 \%$ zirconium nitrate, gave practically the same selective radiation as tungsten. When run at a temperature somewhat above the normal working temperature of the tungsten lamp, a rapid deterioration of the filament took place, accompanied by the formation of an iridescent deposit on the bulb.

Melting Point of Tungsten.-By noting the current required to burn out a tungsten lamp and substituting in the proper currenttemperature equation (Table III) an idea of the melting point of tungsten may be obtained. Lamps I and 5 were burned out, at temperatures of $2950^{\circ}$ and $2850^{\circ} \mathrm{C}$. respectively, which indicates a mean true temperature of about $3200^{\circ} \mathrm{C}$. for the melting point of tungsten. Both filaments formed shiny beads, indicating a true melt and not a disintegration due to evaporation as in the case of carbon filaments. There was no appreciable deposit in the bulbs after burning ont. It would appear that tungsten has the highest melting point yet measured.

\section{TANTALUM LAMPS.}

We have thus far examined only two tantalum lamps, whose current-temperature equations are given in Table $\mathrm{V}$.

TABLE V.

Equations for Tantalum Lamps.

\begin{tabular}{c|l|c}
\hline Lamp No. & Color & Equation \\
\cline { 2 - 3 } 8 & Red & $\mathrm{I}=-0.0125+0.0000538 \mathrm{t}+0.0000000840 \mathrm{t}^{2}$ \\
8 & Green & $\mathrm{I}=-0.0392+0.0000901 \mathrm{t}+0.0000000687 \mathrm{t}^{2}$ \\
8 & Blue & $\mathrm{I}=-0.0607+0.000125 \mathrm{t}+0.0000000531 \mathrm{t}^{2}$ \\
9 & Red & $\mathrm{I}=-0.0176+0.0000617 \mathrm{t}+0.0000000810 \mathrm{t}^{2}$ \\
\hline
\end{tabular}


The filament of No. 9 had been broken, and rewelded by shaking. No. 8 was the ordinary rro volt lamp. At rio volts the current was 0.380 ampere, indicating a temperature of $1865^{\circ} \mathrm{C}$, or a true temperature of about $2000^{\circ} \mathrm{C}$. (See Table VI.) This lamp was heated for one hour at the normal temperature of the tungsten lamp, 2I $35^{\circ} \mathrm{C}$., after which a recalibration showed a marked increase in temperature (about $2 \%$ ) for a given current. A further two hours heating at the same temperature showed a further rise of I \% . After standing ten days it recovered almost completely, the temperature of normal burning ( $\mathrm{I} \mathrm{IO} \mathrm{V}$. ) as determined from a new calibration being $1870^{\circ} \mathrm{C}$. Lamp No. 9 was burned at $2200^{\circ} \mathrm{C}$. for seven hours and showed the same phenomena, but to a much greater extent, and there was a very marked blackening of its bulb.

The increase in efficiency of these metal filament lamps in the early stages of burning is well known. The above experiments indicate a rise in temperature during this stage of the burning. Sufficient data are not yet at hand to determine whether this is due to a smoothing of the surface as has been suggested or to an improvement in the vacuum with burning. If the increase in efficiency is due to an increase in the polish of the surface, and therefore in the selectivity of the radiation, it would probably result in further separating the red and blue calibration curves.

Selective Radiation.-In Table VI are given the results of measurements on the selective radiation of tantalum, as obtained with lamp No. 8.

TABLE VI.

Selective Radiation of Tantalum.

\begin{tabular}{l|l|l|c}
\hline \multicolumn{3}{|c|}{ Black Body Temperatures } & \multirow{2}{*}{$\begin{array}{c}\text { Approximate True } \\
\text { Temperature }\end{array}$} \\
\cline { 1 - 2 } Red $\lambda=0.66$ & Green $\lambda=0.55$ & Blue $\lambda=0.47$ & \\
\hline $1300^{\circ} \mathrm{C}$ & $1320^{\circ} \mathrm{C}$ & $1330^{\circ} \mathrm{C}$ & $1360^{\circ} \mathrm{C}$ \\
$1700^{\circ}$ & $1727^{\circ}$ & $1752^{\circ}$ & $1800^{\circ}$ \\
$2100^{\circ}$ & $2147^{\circ}$ & $2198^{\circ}$ & $2300^{\circ}$ \\
\hline
\end{tabular}

CARBON LAMPS.

For the sake of comparison with the metal filament lamps a study was made of the temperature behavior of some of the ordinary types 
of carbon filament lamps, including 4, 3.5, and 3.I watt lamps. The current-temperature equations of five of these lamps are given in Table VII.

TABLE VII.

Equations of Carbon Filament Lamps.

\begin{tabular}{|c|c|c|c|}
\hline \multirow{2}{*}{$\begin{array}{l}\text { Lamp } \\
\text { No. }\end{array}$} & \multicolumn{2}{|c|}{ Type } & \multirow{2}{*}{ Equation } \\
\hline & Volts & Watts & \\
\hline 3 & 50 & 4 & $\mathrm{I}=0.156-0.000223 \mathrm{t} \quad+0.000000532 \mathrm{t}^{2}$ \\
\hline 4 & 50 & 4 & $\mathrm{I}=.092-0.0000860 \mathrm{t}+0.000000460 \mathrm{t}^{2}$ \\
\hline 6 & 50 & 4 & $\mathrm{I}=.087+0.0000392 \mathrm{t}+0.000000388 \mathrm{t}^{2}$ \\
\hline 7 & 50 & 4 & $I=.166-0.00000140 \mathrm{t}+0.000000394 \mathrm{t}^{2}$ \\
\hline 7 & \multicolumn{2}{|c|}{ After $2200^{\circ}$} & $I=.066+0.000109 t \quad+0.000000352 t^{2}$ \\
\hline 13 & 110 & 3.1 & $\mathrm{I}=.067-0.0000916 \mathrm{t}+0.000000156 \mathrm{t}^{2}$ \\
\hline
\end{tabular}

With a view to determining the maximum temperature attainable with carbon filaments, several of these lamps were burned out by quickly increasing the current.

Owing to the rapid deterioration of the carbon filament the maximum temperature that can be attained depends on the rapidity with which the temperature is raised, the thickness and condition of the filament, etc. For these reasons it is impossible to state with precision the temperature at which the filament finally breaks down as the calibration equation no longer applies, but serves, nevertheless, to define a lower limit of the temperature of destructive disintegration, which varied between $2500^{\circ}$ and $2800^{\circ} \mathrm{C}$. for these lamps. Already at the normal working temperature of the tungsten $\left(2 \mathrm{I} 35^{\circ}\right)$ the carbon lamp shows rapid deterioration.

The normal burning temperatures of lamps $3,4,6$, and 7 ranged from $1695^{\circ}$ to $1720^{\circ}$. Lamp No. 7 was burned at $2200^{\circ}$ for $\mathrm{I} 5$ minutes and on recalibration showed a normal temperature of $1670^{\circ}$, or $40^{\circ}$ lower than before. It was again heated one hour at $2200^{\circ}$, when it broke down at the pasted junction. The bulb showed considerable blackening and the resistance of the lamp rose from 36.7 to $4 \mathrm{I} .5$ ohms. 


\section{NORMAL TEMPERATURES.}

The following Table, VIII, gives the normal burning temperatures of both the metal filament and carbon lamps examined.

TABLE VIII.

Normal Burning Temperatures.

\begin{tabular}{l|c|c|c|c}
\hline Type of lamp & Watts & Volts & $\begin{array}{c}\text { Observed Black Body } \\
\text { Temperatures (Red) }\end{array}$ & $\begin{array}{c}\text { Approximate True } \\
\text { Temperature }\end{array}$ \\
\cline { 2 - 2 } Carbon & 4.0 & 50 & $1710^{\circ} \mathrm{C}$ & $1800^{\circ} \mathrm{C}$ \\
“ & 3.5 & 118 & $1760^{\circ}$ & $1850^{\circ}$ \\
“ & 3.1 & 118 & $1860^{\circ}$ & $1950^{\circ}$ \\
Tantalum & 2.0 & 110 & $1865^{\circ}$ & $2000^{\circ}$ \\
Tungsten & 1.0 & 100 & $2135^{\circ}$ & $2300^{\circ}$ \\
\hline
\end{tabular}

\section{GENERAL DISCUSSION.}

At a given true temperature the total energy of thermal radiation, as well as the energy of radiation for every wave length, emitted per unit area by a black body, is greater than that of any other known body. No conclusive experimental evidence has yet been brought forward in contradiction to this general statement. On account of the very large proportion of the energy of total radiation that exists as the longer wave lengths of the infra-red portion of the spectrum that do not excite the sensation of light in the eye, a black body is an inefficient luminous radiator.

Of all metals that can be raised to even a moderately high temperature (say $1500^{\circ}$ or more) platinum departs farthest from black body radiation. For a given true temperature it radiates less total energy, and a larger proportion of this energy exists in the form of the shorter wave lengths which excite the sensation of light. This is the sense in which the term selective radiation is here used. If platinum would stand the high temperatures at which these modern metal filament lamps can be worked, it would therefore have an appreciably higher efficiency than they have. In this sense all solid substances show, in varying degrees, selective radiation, and all are more efficient luminous radiators than a black body. For these reasons, carbon, which is one of the closest approximations to a black 
body, is a less efficient luminous radiator than the metals. It should be remembered, however, that at the same true temperature a carbon filament would emit more light than these metal filaments, although, on account of the greater selective radiation of the metals as shown above, it would be less efficient.

In much of the literature on this subject the marked gain in efficiency of the metal filament lamps is attributed almost entirely to selective radiation, and it is often implied that the radiation is not only selective in the sense above discussed, but similar to that of a gas, which, when electrically excited, can emit strongly in one region of the spectrum while the energy of radiation may be entirely absent for large regions. In support of this view the statement is often made that the character of the light from the tungsten filament is more greenish in appearance than from a carbon filament or from a tantalum filament.

In this connection it should be stated that a few preliminary measurements made on the Nernst glower at low temperatures seem to show that there is an appreciable increase in the selective radiation for green light, the black -body temperature for green light being almost or quite as high as for blue, which is in agreement with the experiments of Kurlbaum and Schulze. ${ }^{2}$ The nature of the conduction and of the chemical processes here involved is as yet but little understood. The undue increase in the emission for green light might suggest the combined effects of radiation from a solid and from a gas. The experiments of Kurlbaum and Schulze show that this effect almost disappears at higher temperatures, and the important fact remains that it is not this type of selective radiation that contributes materially to the efficiency of any of the metal filament lamps, unless there be a considerable effect of this kind in the infra-red.

The measurements above cited show that tantalum is more selective in its radiation than is tungsten, and in all probability would be more efficient than tungsten at the same true temperature. The great gain in efficiency in the tungsten lamp over the tantalum lamp must therefore be attributed to the very much higher temperature at which the tungsten can be worked continuously. Likewise the

\footnotetext{
${ }^{2}$ Kurlbaum and Schulze: Verhandl. d. Deutsch. Phys. Gesell. 5, p. 428; I903.
} 
marked increase in efficiency shown by both tantalum and tungsten lamps over carbon filament lamps is to some extent due to selective radiation, but is rendered possible to a greater extent by the fact that they can be operated at a higher working temperature. The marked gain in efficiency resulting from an increase in the temperature is at once evident from the fact, that at the working temperature of these lamps the intensity of the light emitted varies about as the twelfth power of the temperature, while the energy supplied to the filament varies as a much lower power of the temperature, something of the order of the fifth, varying with the material of which the filament is constructed and the nature of its surface. This is also illustrated by some measurements made by Dr. Lederer ${ }^{3}$ on Osmin lamps, from which it follows that the light increases as the 4.4 power of the voltage, while the energy consumption varies only as the $\mathrm{I} .5$ power of the voltage.

If a very considerable part of the gain in efficiency in the metal filament over carbon filament lamps is to be attributed to the higher working temperature at which they may be operated it may at first sight seem that this conclusion is at variance with the relatively high efficiency of these metal filament lamps in comparison with electric arc lights where the luminous radiation comes from a source whose temperature is over $1500^{\circ}$ higher. But in the arc light the loss of energy by the conduction and radiation of the carbons and by convective circulation is so great that this fact is readily explained.

We are indebted to Mr. J. W. Howell for the carbon ribbon lamps, and to Mr. J. A. Heany for most of the tungsten lamps. 